\title{
AN INNOVATIVE FRAMEWORK FOR MANAGING THE CUSTOMIZATION OF TAILOR-MADE SHOES
}

\author{
Marconi, Marco (1); Papetti, Alessandra (2); Scafà, Martina (2); Rossi, Marta (2); Germani, \\ Michele (2)
}

1: Università degli Studi della Tuscia; 2: Università Politecnica delle Marche

\begin{abstract}
Product customization aims to consider individual customers preferences in the design of new products, in order to directly involve them in the product development process and to maximize their satisfaction. It can be considered a key competitive factor and a "hot topic" in several industrial sectors, including luxury apparel goods and high-end footwear products. However, currently the design and manufacturing of customized shoes are carried out through artisanal and non-standardized processes, based on the individual expertise of operators.

The objective of this study is to define an innovative framework to support the different processes affected by customization. This framework is enabled by different digital technologies, as CAD-based tools, virtual/augmented reality systems, etc., opportunely integrated in the product development process. The main benefits related to the framework implementation in real industrial contexts are an increase of flexibility, the repeatability of processes, a higher efficiency in information exchange, a more effective involvement of final customers, and, as a consequence, the reduction of time to market and production costs for tailor-made shoes.
\end{abstract}

Keywords: Design for X (DfX), Integrated product development, Design process

Contact:

Marconi, Marco

Università degli Studi della Tuscia

Department of Economics, Engineering, Society and Business Organization

Italy

marco.marconi@unitus.it

Cite this article: Marconi, M., Papetti, A., Scafà, M., Rossi, M., Germani, M. (2019) 'An Innovative Framework for Managing the Customization of Tailor-made Shoes', in Proceedings of the 22nd International Conference on Engineering Design (ICED19), Delft, The Netherlands, 5-8 August 2019. DOI:10.1017/dsi.2019.389 


\section{INTRODUCTION}

In recent decades, customization is acquiring increasing importance in several industrial sectors, such as luxury goods and automotive (Kumar, 2004). Industrial firms are working hard to answer the even more exacting customers, by enlarging the variety of the offered products (Takagoshi and Matsubayashi, 2013). Product customization aims to consider individual customer preferences in the design of new products, in order to maximize the satisfaction and the value that customers derive from buying products (Ellena et al., 2018). At the present time, it can be considered a key competitive factor, especially in developed countries where the mass production model is no longer economically sustainable (Wong and Lesmono, 2013). This is evident by analysing the significant increase in the last decade of existing commercial solutions and literature studies about this topic (Fogliatto et al., 2012).

In this context, a change in the design, production and organizational processes is needed. Manufacturing companies must be more flexible to produce very small and heterogeneous lots, and strongly oriented to customers in order to maximize their satisfaction and the added value (Vickery et al., 1999). However, the practical implementation of this new paradigm requires to jointly consider several aspects: production plants, human resources and the external stakeholders (e.g. suppliers). This complex environment is always correlated with a huge amount of information to manage and share (Miceli et al., 2007; Zezulka et al., 2016).

Several literature studies focus on the development of frameworks to support the processes affected by customization (e.g. design, production, order). For instance, Zhang et al. (2010) proposed an integrated order fulfilment system to automatically execute order processing, configure products and process plans, and extract and share real-time data. Bonev et al. (2015) presented a combination of informal and formal methods to design and support the mass customization of product family architectures. The design phase has been also examined by Song and Sakao (2017) who proposed a design framework dedicated to sustainable product/service systems. Klein et al. (2014) focused on the representation and exchange of relevant knowledge during the product development process of customized products.

In recent years, the definition of the Industry 4.0 paradigm favoured the development of novel information-communication technologies (ICT) to be used in industrial processes, such as sensors, cyber physical systems, virtual prototyping technologies, etc. (Ahuett-Garza and Kurfess, 2018). These technologies impact at different levels and strongly affect the product customization. In particular, they contribute in fostering the transition from the traditional mass production to the mass customization, where products are co-designed by producers and customers, and processes have to allow the production of single pieces in a reduced time to market (Helms et al., 2008; Zhang et al., 2017).

Focusing on the industrial sector object of the present study, i.e. the footwear industry, customization is a "hot-topic" both at the academic and industrial levels (Jimeno-Morenilla et al., 2016). Customized and made to measure (MTM) shoes contribute to increase the foot comfort, a crucial parameter for a high customer satisfaction. Literature is full of interesting studies regarding the development of methods and tools to support the customization and personalization of shoes or shoe components (Weerasinghe and Goonetilleke, 2011). Some of them face the 3D foot shape reconstruction with the aim to maximize the shoe fitting (Zhao et al., 2008). The majority are focused on the design of the shoe last. For instance, Luximon and Luximon (2009) proposed a computer-aided design (CAD)-based tool to automate the design phase. Xiong et al. (2010) used a foot scanning as a basis for the shoe last customization. Also, customers with special needs (e.g. diabetic people) are considered in different literature studies (Bernabéu et al., 2013).

Despite the great efforts posed in facing the customization topic, currently in the industrial world the design and customization of high-end footwear products are carried out through artisanal, manually and non-standardized processes, essentially based on the knowledge of experienced operators. Only few studies tried to jointly consider the different aspects involved in the customization, as the exchange of information, the need for advanced design and management tools, etc. (Mandolini et al., 2017; Marconi et al., 2018). The most interesting one has been proposed by Ducq and Vallespir (2008) who defined a reference model for mass customization of fashion products. However, this study only investigated how two different techniques (i.e. IDEF0 and GRAI) can be used to model current and future operations of companies involved in the mass customization, while the description of the supporting tools, the needed technologies and their use scenarios are not sufficiently detailed to be implemented in real applications. 
The present study wants to integrate the state of the art described above by defining a framework to be used for the manufacturing of customized shoes, particularly MTM products. This framework includes all the relevant phases (e.g. requirements definition, shoe design, product manufacturing, information exchange) and is enabled by different technologies, as CAD-based tools, virtual/augmented reality (VR/AR) systems, product database/lifecycle management (PDM/PLM) systems, traceability systems, 3D printing equipment, which support the internal and external stakeholders in satisfying the customer requirements. The final objective is to support companies involved in the manufacturing of high-end footwear products in increasing the overall efficiency of their customization processes. Specifically, the proposed framework aims at: (i) integrating the production of standard and customized products in the same production lines, (ii) increasing the flexibility of internal processes in order to rapidly answer to specific customer requirements, (iii) making the customization process more efficient in terms of waste of time/resources (human and economic), (iv) making the process more repeatable and less dependent by the know-how of expert operators, (v) increasing the efficiency of the information exchange avoiding loss or misunderstanding of data, (vi) further involving the final end-user in the product configuration, and (vii) sensibly reducing the time to market for personalized products.

\section{TRADITIONAL PRODUCT DEVELOPMENT PROCESS FOR CUSTOMIZED SHOES}

The traditional process has been defined by mapping the product development process of different Italian companies of the footwear industry. The analysed processes are very similar and generally exhibit the same strengths and weaknesses. Most of the companies operating in the high-end footwear sector still have a semi-craft process. This process has numerous advantages in terms of product quality but also many issues related to the inefficiency of the production process and waste of resources.

The traditional process to develop customized shoes starts when customer goes to fairs or shops to order shoes. In this first phase, the customer interacts with the clerk for shoes features definition (configuration phase). Customers' choices are influenced by the current shoes collection, present in the store or catalogue. Generally, the clerk does not have any tools to help clients in shoes configuration. The result is a personalized shoe that does not consider technical constraints. At the end of this first phase, the clerk sends the order via e-mail to company, including all customer requirements.

The order is received by the sales office that collaborates with Managing Directors to preliminary evaluate the order feasibility. If the order is considered acceptable, the artisan, who is in charge for the whole customization process, and the sales employee go to the customer for the foot measurement. Considering that high-end footwear companies generally serve the global market, this is a relevant inefficiency both in terms of waste of time (to reach the customer) and money (long distance trips).

During the foot measurement phase, the artisan does not utilize any supporting tool. The common procedure foresees the manual measurements through meter sticks and blueprints. Based on the foot shape and his/her experience, he/she recommends to the client the most suitable shoe model and last. The sales employee finalizes the customer's order on paper commission copy and sends it to the company via e-mail. This phase is one of the most critical. Firstly, only the artisan has the knowledge to take foot measurements in the right way. Secondly, a loss of information often occurs (e.g. specific client foot measures, shoes' technical or stylistic variations). In some cases, there may be many phone calls and e-mail exchange between the customer and the company to clarify the order details.

When all shoe details are defined the technical office creates the technical sheet and generates the production documentation, so that the manufacturing can start. Since high-end footwear firms are often small companies, both the standard and the MTM orders are managed in the standard production line, with clear inefficiencies. At most, the production documentation related to MTM orders is differentiated (e.g. different paper colour) from the standard documentation, to inform the production line operators.

During the manufacturing phase, at first, the artisan, with the support of a shoe last manufacturing company realizes a wooden (or plastic) last specifically designed for the customer's foot. Then the modelling department manually realizes a $2 \mathrm{D}$ paper model of the shoe upper, without the support of $\mathrm{CAD}$ or similar technologies. Only at this stage the specifications are deeply analysed from a technical and stylistic points of view and the real technical feasibility can be verified. If all the customer requirements cannot be satisfied, a negotiation phase starts again. Through numerous phone calls and emails, the sales employee tries to find a trade-off solution between the customer requirements and the technical constraints. Customers who require this kind of products are usually very demanding, thus this 
further negotiation phase is generally very long and complex, entailing a loss of time and an increase of production costs. Without the possibility of visual feedbacks, it is very difficult to convince customers that some stylistic combinations are not possible. Sometimes it is even necessary to reach the prototyping phase to become aware of incorrect choices made during the configuration and design phases.

When the last and the 2D model paper are ready the prototype production can start. The first shoe prototype is usually made of less valuable materials. When the prototype is ready the artisan and the sales employee go back to the customer for the first test fitting. If the customer is not fully satisfied (e.g. not acceptable comfort level, stylistic changes required), an iterative process of last/foot model modification and test fitting starts, until an acceptable solution is reached. Numerous tests fitting can be caused by an unusual foot shape, as well as by errors made during the manual foot measurement (the process is not repeatable and grounded on the artisan experience). Obviously, the current process causes two main problems: a delay in the delivery time of the final product, and a waste of money due to the manufacturing of more than one physical prototype and the need of several trips for test fitting.

Once the prototype is approved, the final shoe manufacturing can start. The most experienced operators are involved, and the artisan personally monitor the whole process. When the shoes are ready, the quality check is carried out. Shoes are then photographed and packed in customized boxes (e.g. wooden box, box with the customer initials), together with accompanying goods (e.g. polishing products, letter of thanks). Finally, the artisan and the sales employee personally deliver shoes to customers.

As a summary, Figure 1 reports the entire traditional product development process.

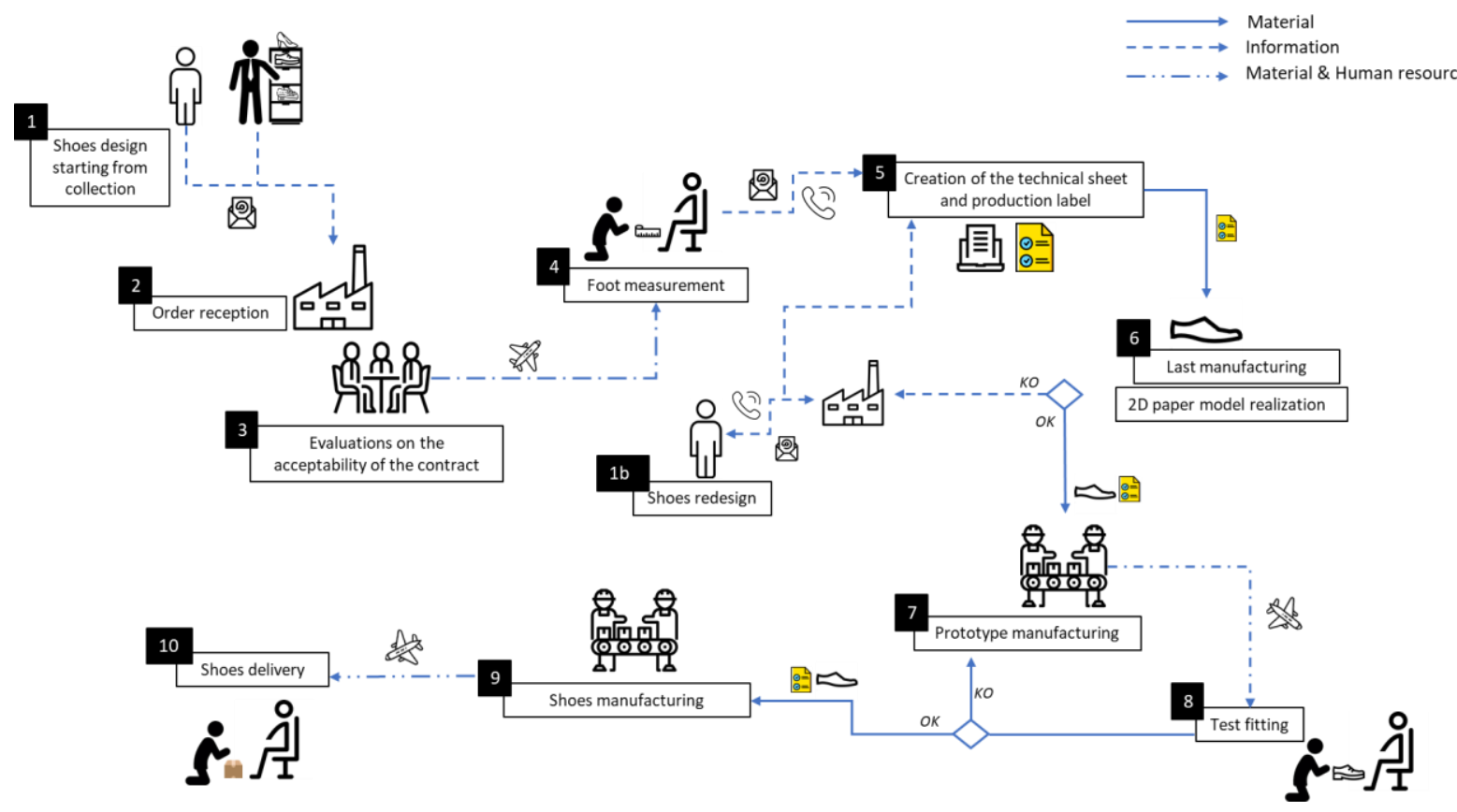

Figure 1. Traditional development process of customized shoes

\section{THE PROPOSED CUSTOMIZATION PROCESS}

As described, an apparently simple sale model implies a series of technical and economic issues that significantly affect the customer experience and the process efficiency.

The proposed framework (Figure 2) intends to tackle these aspects by efficaciously combining tools and technologies able to support the adoption of a new product development process based on "see, design, buy" paradigm and customized production up to "one of a kind". This process is driven by two common pillars of companies that produce luxury apparel goods: user-centred design and tailor-made production. In the proposed customization process, the product conception starts from the customer who can configure its ideal footwear at company stores. In this way, stores become a place of co-design between customer and company employees, making the shopping experience unique. It means to support the customer to conceive the product also making him/her inspired by company collections. At the same time, the creation of customized products cannot disregard the complete control of the entire production cycle, of which the design is the starting point. This value proposition, indeed, strongly affects all downstream processes and implies new technologies for design, production and data management. 


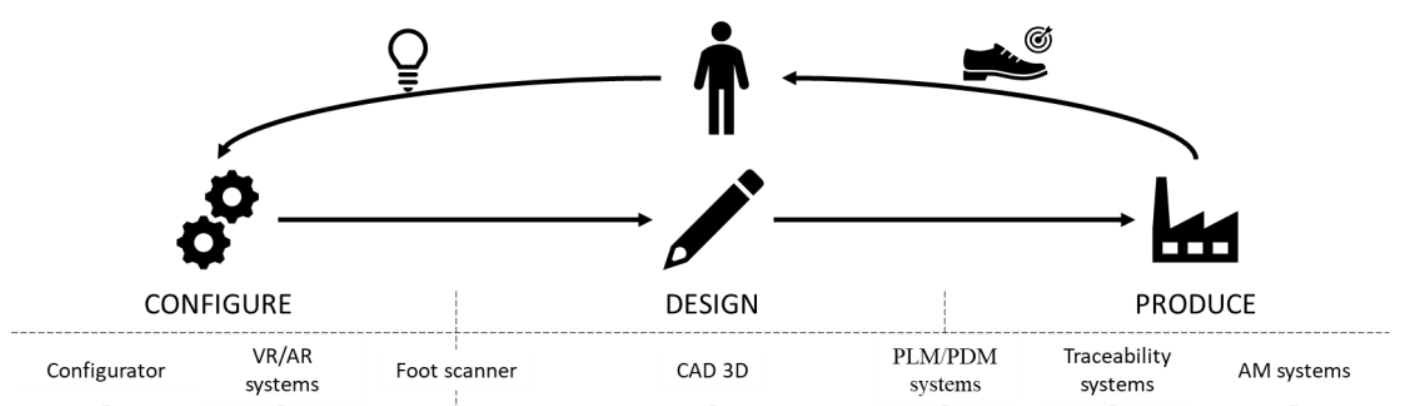

(b)
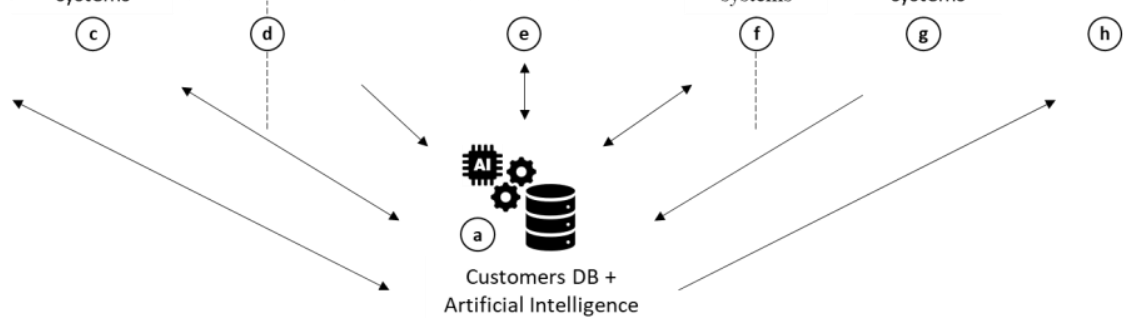

(h)

Figure 2. Tools and technologies supporting the proposed shoes customization process

In particular, the following tools have to be exploited in different phases of the product development process:

- A 3D CAD software tool dedicated to shoe design, which allows creating new sketches in a quicker and more precise way, and easily adapting a single design to varying materials and patterns;

- A CAD-based product configurator that intelligently manages the product data, 3D models and company knowledge in order to offer to customers the opportunity to configure its ideal shoe. This tool has to be based on specific configuration rules to guarantee a preliminary feasibility of the configured solutions. In this way, it is possible to offer a quality service that simultaneously gives free space to the customer's creativity, and ensures the physical realization of the product;

- VR/AR systems to be used as design technologies at company's boutiques in order to fully involve the customer in the design phase. VR offers the customer the opportunity to see a virtual prototype of the configured shoe that reflects (both visually and tactile) the real one in the more faithfully possible manner. Through AR, it is also possible to enrich the customer's sensorial perception with digital information (e.g. accessories, materials), allowing him/her to virtually wear its "creation";

- A 3D laser scanner, which allows scanning the customer's foot without contact and the memorization of a point cloud. The related software application is able to read the point cloud and automatically extract the main biometric parameters of the customer's foot. These parameters are used to search in the company database the last that best fit with the customer's foot in order to guarantee the maximum comfort;

- Traceability systems (e.g. RFID) able to monitor the status of each order and track the flow of materials within the various production departments (from components warehouse to product ready for delivery) in order to keep time to market under control and avoid excessive and costly inventories. It is an important tool for controlling the efficiency and quality of production processes, preventing bottlenecks and defects. Moreover, it allows involving the customer in the production phase, since he/she can constantly track the status of his/her order;

- Tools for managing product and process data (PDM/PLM) that aim to guarantee an efficient sharing of information along the whole flow of conception, configuration, production and sale of customized shoes and optimize the management of the flow of materials, components and products;

- $\quad 3 \mathrm{D}$ printing technologies to make possible the accessories co-design: the customer can request the creation of fully customized accessories starting from photos or sketches. In this case, the additive manufacturing (AM) technology that appears to be the most promising is the laser sintering of metal powders, such as titanium, steel or nickel-chromium, which appear suitable materials for the creation of accessories for customized footwears.

To guarantee a high-quality user experience it is necessary to offer products and services able to fit specific customers characteristics (e.g. biometric characteristics) and aesthetic/functional requirements. It includes the use in a new and innovative way of a biometric recognition system, that is a patternrecognition consisting of two phases: enrolment and recognition. In particular, the customer feature set is acquired and stored in a database, together with his/her preferences and previous choices. Such database 
communicates with all tools cited above in order to consider the customer in all phases of the product development process. In this way, through the implementation of machine learning algorithms, it will be possible to suggest configurations capable of responding both to the needs of already loyal customers and to those of new customers whose characteristics are very similar to those present in the database. This approach will also allow the acquisition of a very large quantity of statistical data in an easy way, with the aim to upgrade the rationale behind the configurator.

Table 1 summarizes potential benefits and limits of technologies included in the proposed framework.

Table 1. Tools benefits and limits

\begin{tabular}{|l|l|l|}
\hline Tool & Potential Benefits & Potential Limits \\
\hline CAD 3D & $\begin{array}{l}\text { Design speed and accuracy } \bullet \text { Easy } \\
\text { corrections, sharing and repetitive } \\
\text { parts management } \bullet \text { More realistic } \\
\text { designs } \bullet \text { Link with CAM machines or } \\
\text { 3D printing technologies }\end{array}$ & $\begin{array}{l}\text { Initial costs } \bullet \text { Learning time } \bullet \text { Training } \\
\text { time and cost } \bullet \text { Need for SW updating } \\
\bullet \text { Craft component reduction }\end{array}$ \\
\hline Configurator & $\begin{array}{l}\text { Customization } \bullet \text { Real-time feedback } \bullet \\
\text { Product technical feasibility }\end{array}$ & $\begin{array}{l}\text { Initial costs } \bullet \text { Training time and cost } \bullet \\
\text { Knowledge formalization } \bullet \\
\text { Management of not configurable MTM } \\
\text { solutions }\end{array}$ \\
\hline $\begin{array}{l}\text { VR/AR } \\
\text { systems }\end{array}$ & $\begin{array}{l}\text { Customer experience improvement } \\
\text { Foot scanner }\end{array}$ & $\begin{array}{l}\text { Initial costs } \bullet \text { Prototype fidelity } \bullet \\
\text { System intrusiveness }\end{array}$ \\
\hline $\begin{array}{l}\text { Greater success in the fitting test } \bullet \\
\text { Breaking the barriers to knowledge } \\
\text { sharing }\end{array}$ & $\begin{array}{l}\text { Initial costs } \bullet \text { Technology acceptance } \\
\text { Customer perceived value }\end{array}$ \\
\hline systems & $\begin{array}{l}\text { Traceability of materials, products and } \\
\text { orders } \bullet \text { Reduction of time to market } \\
\text { and inventory costs } \bullet \text { Reduction of } \\
\text { bottlenecks and defects }\end{array}$ & $\begin{array}{l}\text { Initial costs } \bullet \text { Implementation } \\
\text { challenges }\end{array}$ \\
\hline $\begin{array}{l}\text { PLM/PDM } \\
\text { systems }\end{array}$ & $\begin{array}{l}\text { Information sharing and management } \\
\bullet \text { Reduced time to market }\end{array}$ & $\begin{array}{l}\text { Initial costs } \bullet \text { Training time and cost } \bullet \\
\text { Implementation challenges } \bullet \text { User } \\
\text { resistance }\end{array}$ \\
\hline AM systems & $\begin{array}{l}\text { Flexibility } \bullet \text { Creative (co)design and } \\
\text { customization freedom } \bullet \text { Product } \\
\text { testing } \bullet \text { Time to market reduction }\end{array}$ & $\begin{array}{l}\text { Initial costs } \bullet \text { Quality requirements } \\
\text { satisfaction }\end{array}$ \\
\hline $\begin{array}{l}\text { Artificial } \\
\text { intelligence }\end{array}$ & $\begin{array}{l}\text { Shoe configuration fitting customer's } \\
\text { needs }\end{array}$ & $\begin{array}{l}\text { User and system training time and cost } \\
\bullet \text { Data availability and quality }\end{array}$ \\
\hline
\end{tabular}

The introduction and integration of the abovementioned technologies allows improving the product development process for MTM shoes, as demonstrated by the workflow shown in Figure 3. The customer goes at company store with the intention of buying tailor-made shoes. The customers DB allows checking if historic data are available (e.g. foot measures or previous orders) and, in that case, loading the user profile to start the shoe configuration. In case of new customers, the clerk registers $\mathrm{him} /$ her and proceeds with the scan of the foot. In both cases, the CAD-based configurator suggests, as starting point, the last that best suits the customer's foot. It triggers a sort of workshop of footwear design, where the customer interacts with expert system and people to create a customized shoe that satisfies his needs. Appropriate rules, implemented in the configurator, allow giving a preliminary feedback to the customer about the feasibility of his/her solution, avoiding future issues. The second feedback is provided by the high-fidelity virtual model, according to which the customer can improve the configuration. He/she has also the possibility to create customized accessories (e.g. buckles, eyelets, initials, etc.) and visualize them on the virtual model. Through the use of appropriate markers and a software application for mobile devices, the AR system is able to project the rendering of the shoe over the customer's foot in order to give him/her the sensation of wearing it in real time. It is the final checking point of the shoe design. 
Once the customer is satisfied, the shoe order is formalized, and all information generated in the store (e.g. biometric parameters, shoe configuration, accessories) is transferred to the PDM/PLM system, making it available for the production process. The technical sheet and production documentation are automatically generated, without information losses. This digitally-enabled process is quicker and more efficient, maintaining the right balance between quality, craftsmanship and time to market.

The production follows the same steps described in the traditional process, but the expected success in the fitting test is greater, and the iterative phases are eliminated or at least reduced. Moreover, the AM allows combining a great variability of shapes and geometries achievable with very low set-up and production times, matching well with the necessity to manage unitary or micro-lot orders.

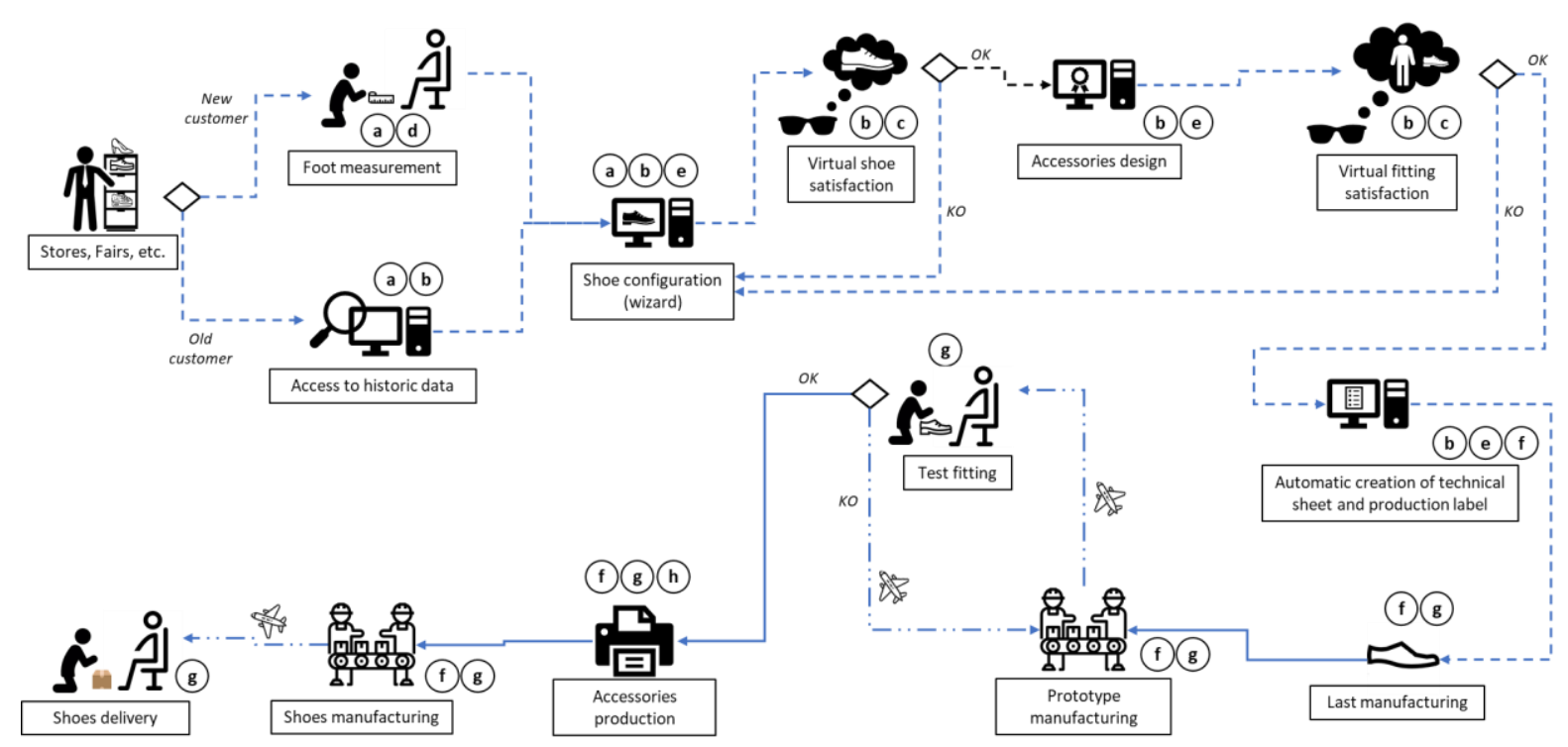

Figure 3. The proposed customization process for MTM shoes

The proposed framework also enables a lower level of shoe customization (Figure 4), the Make to Order (MTO), which does not include a tailor-made production. The customer can configure his/her shoes at home rather than choosing one from the catalogue. The online CAD-based configurator guarantees the same functionalities described above. In this case, the customer can manually input the foot measure enabling the suggestion of the shoe model that best suits his/her foot. Existing lasts are exploited in this process, increasing the importance of the configurator suggestion (based on machine learning algorithms), which is the only feedback received by customer during the whole product development.

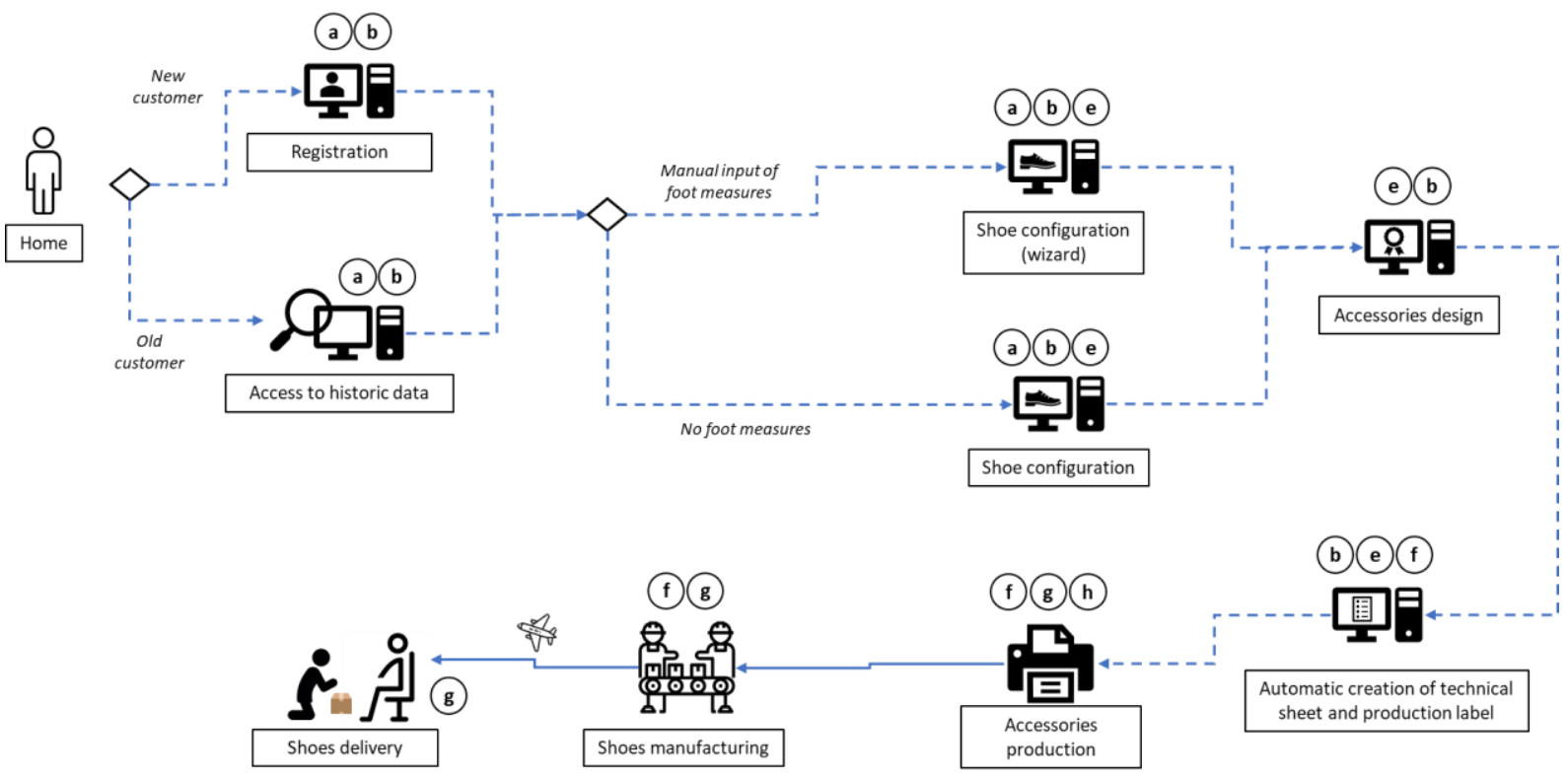

Figure 4. The proposed customization process for MTO shoes 


\section{DISCUSSION AND CONCLUDING REMARKS}

Currently, the proposed framework has not yet been implemented in real industrial contexts. Therefore, it is not possible to describe the experimentation phase and report the obtained quantitative findings. Only potential benefits and drawbacks deriving from the implementation of the proposed framework can be preliminarily discussed, while the experimentation in different real industrial contexts together with the assessment of quantitative and qualitative benefits currently represent a future work.

As said before, customer experience, product quality and efficiency of design, manufacturing and organizational processes are the fundamental pillars that companies belonging to the high-end footwear sector have to take into account for maintaining the competitiveness on the market. The proposed innovative framework can help companies in improving their customized product development process. The full set of integrated enabling technologies allows companies to offer a better service to customers, directly involving them in the product configuration, as well as to minimize their internal inefficiencies with respect to the standard situation, where processes are grounded on individual skills of expert operators. In this situation the processes are not optimized and repeatable, leading to several iterative loops (configuration-design-feasibility-redesign-feasibilityproduction-test). In addition, the framework includes technologies for an efficient data management, elaboration and exchange (i.e. centralized databases, machine learning algorithms, PDM/PLM systems). This allows reducing loss of information, time for communication among internal and external stakeholders, as well as to make the final customer aware about the status of an order. As a consequence, the product quality will be higher, with a minimization of the process bottlenecks. This could potentially lead to a reduction of the time to market and costs, with benefits in terms of brand positioning, customer loyalty, as well as from the economic point of view. However, the customer experience could get worse as he/she may not immediately perceive the added value of new technologies. Likewise, there may be difficulties in the process of knowledge formalization and implementation of the new workflow. In addition, the operator training phase could be burdensome in terms of time and therefore of cost.

The following Table 2 compares the current and future customization processes, considering the single product development phases.

Table 2. Comparison among the current and optimized workflows for each product development phase

\begin{tabular}{|c|c|c|c|c|}
\hline $\begin{array}{l}\text { Product } \\
\text { development } \\
\text { phases }\end{array}$ & Current workflow & Optimized workflow & $\begin{array}{l}\text { Potential } \\
\text { Benefits }\end{array}$ & Potential Limits \\
\hline Configuration & $\begin{array}{l}\text { At store: } \\
\text { - No historic data } \\
\text { available } \\
\text { - Manual foot } \\
\text { measurement } \\
\text { - Configuration } \\
\text { starts from the } \\
\text { standard } \\
\text { collection } \\
\text { - No feedbacks on } \\
\text { feasibility } \\
\text { available } \\
\text { - Information } \\
\text { exchanged } \\
\text { through e-mail } \\
\text { and phone calls. } \\
\text { At home: } \\
\text { - No foot } \\
\text { measures }\end{array}$ & $\begin{array}{l}\text { At store: } \\
\text { - Historic data available } \\
\text { - Foot scanning } \\
\text { - Configuration starts } \\
\text { from the shoe last and } \\
\text { model that best suits } \\
\text { the customer foot } \\
\text { - Technical feedbacks } \\
\text { by configuration rules } \\
\text { - Aesthetic feedbacks } \\
\text { by virtual shoe fitting } \\
\text { - Digital information } \\
\text { flow } \\
\\
\text { At home: } \\
\text { Manual input of foot } \\
\text { measures } \\
\text { Configuration starts } \\
\text { from the existing last }\end{array}$ & $\begin{array}{l}\text { - Information } \\
\text { loss reduction } \\
\text { - Optimization of } \\
\text { materials and } \\
\text { resources flows } \\
\text { - Customer } \\
\text { involvement } \\
\text { during product } \\
\text { configuration } \\
\text { - Time to market } \\
\text { reduction }\end{array}$ & $\begin{array}{l}\text { - Possible } \\
\text { difficulty related } \\
\text { to customer's } \\
\text { technology } \\
\text { acceptance } \\
\text { - Difficulty in } \\
\text { formalization of } \\
\text { configuration } \\
\text { rules and } \\
\text { technical } \\
\text { knowledge }\end{array}$ \\
\hline
\end{tabular}




\begin{tabular}{|c|c|c|c|c|}
\hline & $\begin{array}{l}\text { - Shoe selection } \\
\text { from catalogue } \\
\text { - No feedbacks } \\
\text { on feasibility } \\
\text { available }\end{array}$ & $\begin{array}{l}\text { that best suits the } \\
\text { customer foot } \\
\text { Technical feedbacks by } \\
\text { configuration rules } \\
\text { Aesthetic feedbacks by } \\
\text { 3D shoe model }\end{array}$ & & \\
\hline Design & $\begin{array}{l}\text { - Papery } \\
\text { information flow } \\
\text { - Centralized } \\
\text { knowledge } \\
\text { - Time consuming } \\
\text { (re)design } \\
\text { activities } \\
\text { - Accessories } \\
\text { requirements list }\end{array}$ & $\begin{array}{l}\text { - Digital information } \\
\text { flow } \\
\text { - Knowledge sharing } \\
\text { - Optimized (re)design } \\
\text { activities } \\
\text { - Accessories co-design }\end{array}$ & $\begin{array}{l}\text { - More efficient } \\
\text { design activities } \\
\text { - Re-design } \\
\text { activities } \\
\text { reduction } \\
\text { - Optimization of } \\
\text { the flow of data } \\
\text { between the } \\
\text { design and } \\
\text { production } \\
\text { phases }\end{array}$ & $\begin{array}{l}\text { - Difficulty and } \\
\text { time/cost loss } \\
\text { to train } \\
\text { operators in the } \\
\text { use of new } \\
\text { technologies }\end{array}$ \\
\hline Production & $\begin{array}{l}\text { - Papery } \\
\text { information flow } \\
\text { - Manual } \\
\text { traceability of } \\
\text { production } \\
\text { process by artisan } \\
\text { - No traceability } \\
\text { of order status } \\
\text { - Standard } \\
\text { manufacturing of } \\
\text { accessories } \\
\text { - Feedbacks by } \\
\text { test fitting. }\end{array}$ & $\begin{array}{l}\text { - Digital information } \\
\text { flow and management } \\
\text { through PLM/PDM } \\
\text { - Automatic traceability } \\
\text { of production process } \\
\text { - Traceability of order } \\
\text { status by customer } \\
\text { - AM of accessories } \\
\text { - Feedbacks by test } \\
\text { fitting }\end{array}$ & $\begin{array}{l}\text { - Improvement } \\
\text { of production } \\
\text { process efficiency } \\
\text { and quality, } \\
\text { preventing } \\
\text { bottlenecks and } \\
\text { defects } \\
\text { - Reduction of } \\
\text { production time } \\
\text { and cost } \\
\text { - Greater success } \\
\text { in the fitting test. }\end{array}$ & $\begin{array}{l}\text { - Difficulty to } \\
\text { implement } \\
\text { digital flow } \\
\text { because of } \\
\text { operators } \\
\text { resistance } \\
\text { - Additional } \\
\text { difficulty to } \\
\text { monitor shoes } \\
\text { quality. }\end{array}$ \\
\hline
\end{tabular}

\section{REFERENCES}

Ahuett-Garza, H. and Kurfess, T. (2018), "A brief discussion on the trends of habilitating technologies for Industry 4.0 and Smart manufacturing”, Manufacturing Letters, Vol. 15 No. B, pp. 60-63. https://doi.org/10.1016/j.mfglet.2018.02.011.

Bernabéu, J.A., Germani, M., Mandolini, M., Mengoni, M., Nester, C., Preece, S. and Raffaeli, R. (2013), “CAD tools for designing shoe lasts for people with diabetes", Computer-Aided Design, Vol. 45 No. 6, pp. 977-990. https://doi.org/10.1016/j.cad.2012.12.005.

Bonev, M., Hvam, L., Clarkson, J. and Maier, A. (2015), "Formal computer-aided product family architecture design for mass customization”, Computers in Industry, Vol. 74, pp. 58-70. https://doi.org/10.1016/j.compind.2015.07.006.

Ducq, Y. and Vallespir, B. (2008), "Reference Models for Mass Customisation Production of High Fashionable Products: Application to the Shoe Manufacturing Domain", In: T. Koch, 257, Lean Business Systems and Beyond, IFIP - The International Federation for Information Processing, Springer, Boston, pp. 165-173. https://doi.org/10.1007/978-0-387-77249-3_17.

Ellena, T., Mustafa, H., Subic, A. and Pang, T.Y. (2018), “A design framework for the mass customisation of custom-fit bicycle helmet models", International Journal of Industrial Ergonomics, Vol. 64, pp. 122-133. https://doi.org/10.1016/j.ergon.2018.01.005.

Fogliatto, F.S., da Silveira, G.J.C. and Borenstein, D. (2012), “The mass customization decade: An updated review of the literature", International Journal of Production Economics, Vol. 138 No. 1, pp. 14-25. https://doi.org/10.1016/j.ijpe.2012.03.002.

Helms, M.M., Ahmadi, M., Jih, W.J.K. and Ettkin, L.P. (2008), “Technologies in support of mass customization strategy: Exploring the linkages between e-commerce and knowledge management", Computers in Industry, Vol. 59 No. 4, pp. 351-363. https://doi.org/10.1016/j.compind.2007.09.003. 
Jimeno-Morenilla, A., Garcia-Rodriguez, J., Orts, S. and Davia-Aracil, M. (2016), "GNG based foot reconstruction for custom footwear manufacturing”, Computers in Industry, Vol. 75, pp. 116-126. https://doi.org/10.1016/j.compind.2015.06.002.

Klein, P., Pugliese, D., Lützenberger, J., Colombo, G. and Thoben, K.-D. (2014), "Exchange Of Knowledge In Customized Product Development Processes", Procedia CIRP, Vol. 21, pp. 99-104. https://doi.org/10.1016/j.procir.2014.03.149.

Kumar, A. (2004), "Mass Customization: Metrics and Modularity", The International Journal of Flexible Manufacturing Systems, Vol. 16 No. 4, pp. 287-311. https://doi.org/10.1007/s10696-005-5169-3.

Luximon, A. and Luximon, Y. (2009), "Shoe-last design innovation for better shoe fitting", Computers in Industry, Vol. 60 No. 8, pp. 621-628. https://doi.org/10.1016/j.compind.2009.05.015.

Mandolini, M., Brunzini, A. and Germani, M. (2017), "A collaborative web-based platform for the prescription of Custom-Made Insoles”, Advanced Engineering Informatics, Vol. 33, pp. 360-373. https://doi.org/10.1016/j.aei.2016.10.004.

Marconi, M., Manieri, S., Germani, M. and Raffaeli, R. (2019), “A Digitally-enabled Integrated Approach to Design and Manufacture Shoe Lasts”, Computer-Aided Design \& Applications, Vol. 16 No. 3 , pp. 593-610. https://doi.org/10.14733/cadaps.2019.593-610.

Miceli, G.N., Ricotta, F. and Costabile, M. (2007), "Customizing customization: A conceptual framework for interactive personalization", Journal of Interactive Marketing, Vol. 21 No. 2, pp. 6-25. https://doi.org/10.1002/dir.20076.

Song, W. and Sakao, T. (2017), "A customization-oriented framework for design of sustainable product/service system”, Journal of Cleaner Production, Vol. 140 No. 3, pp. 1672-1685. https://doi.org/10.1016/j.jclepro.2016.09.111.

Takagoshi, N. and Matsubayahi, N. (2013), "Customization competition between branded firms: Continuous extension of product line from core product", European Journal of Operational Research, Vol. 225 No. 2, pp. 337-352. https://doi.org/10.1016/j.ejor.2012.10.001.

Vickery, S., Dröge, C. and Germain, R. (1999), “The relationship between product customization and organizational structure”, Journal of Operations Management, Vol. 17 No. 4, pp. 377-391. https://doi.org/10.1016/S0272-6963(98)00053-9.

Weerasinghe, T.W. and Goonetilleke, R.S. (2011), "Getting to the bottom of footwear customization", Journal of Systems Science and Systems Engineering, Vol. 20 No. 3, pp. 310-322. https://doi.org/10.1007/s11518-011-5171-0.

Wong, H. and Lesmono, D. (2013), "On the evaluation of product customization strategies in a vertically differentiated market”, International Journal of Production Economics, Vol. 144 No. 1, pp. 105-117. https://doi.org/10.1016/j.ijpe.2013.01.023.

Xiong, S., Zhao, J., Jiang, Z. and Dong, M. (2010), “A computer-aided design system for foot-feature-based shoe last customization”, The International Journal of Advanced Manufacturing Technology, Vol. 46 No. 1-4, pp. 11-19. https://doi.org/10.1007/s00170-009-2087-7.

Zezulka, S., Marcon, P., Vesely, I. and Sajdi, O. (2016), "Industry 4.0 - An Introduction in the phenomenon”, IFAC-PapersOnLine, Vol. 49 No. 25, pp. 8-12. https://doi.org/10.1016/j.ifacol.2016.12.002.

Zhang, L.L., Lee, C.K.M. and Xu, Q. (2010), "Towards product customization: An integrated order fulfillment system”, Computers in Industry, Vol. 61 No. 3, pp. 213-222. https://doi.org/10.1016/j.compind.2009.09.003.

Zhang, S., Xu, J., Gou, H. and Tan, J. (2017), “A Research Review on the Key Technologies of Intelligent Design for Customized Products”, Engineering, Vol. 3 No. 5, pp. 631-640. https://doi.org/10.1016/J.ENG.2017.04.005.

Zhao, J., Xiong, S., Bu, Y. and Goonetilleke, R.S. (2008), "Computerized girth determination for custom footwear manufacture”, Computers \& Industrial Engineering, Vol. 54 No. 3, pp. 359-373. https://doi.org/10.1016/j.cie.2007.07.015. 